\title{
BIOMIMICRY ARCHITECTURE, FROM THE INSPIRATION BY NATURE TO THE INNOVATION OF THE SAHARAN ARCHITECTURE
}

\author{
Yassine Mohammed Benyoucef, Andrey Razin \\ Peoples' Friendship University of Russia \\ Miklukho-Maklaya Street, 6, Moscow, Russia \\ b.yassine@mail.ru
}

\begin{abstract}
Biomimicry is an old approach, but in the scientific conceptualization is new, as an approach of innovation based on the emulation of Nature, in recent years, this approach brings many potential theories and innovations in the architecture field. Indeed, these innovations have changed our view towards other Natural organisms also to the design processes in architecture, now the use of the biomimicry approach allows the application of a great sustainable development. The Sahara area is heading towards a sustainable policy with the desire to develop this rich context in terms of architecture. This article discuss the using of biomimetic strategy in the sustainable development of Saharan architecture.

The aim of the article is to present a synthesis of biomimicry approach and propose the biomimicry as a solution for the development of Saharan architecture which can use this approach as a sustainable and innovation strategy. The biomimicry is the solution for effective strategies of development and can have a great potential point to meet the current challenges of designing efficient for forms or structures, energy efficiency, and climate issues. Moreover, the Sahara can be a favorable soil for great changes, the use of this approach is the key for the most optimal strategies and sustainable development of the Saharan architecture. .
\end{abstract}

\section{Keywords}

Biomimicry, Sahara, architecture, nature, innovation, technology.

\section{Introduction}

Biomimicry, defined as a new engineering inspired by Nature, for innovation in different fields, design, transportation, architecture. As an interdisciplinary field, architecture is influenced by many aspects of the natural and technology and social sciences. Among these influences, the inspiration of biology is currently dominant. The framework of bio-inspired design has evolved and turned into different innovative approaches, largely due to the development of computing and its use in architecture (Chayaamor-Heil, Guéna, 2018).

After the emergence of this approach that makes the relationship between biology and architecture and also technology in architecture, Biomimicry defines as an innovative constructive approach to designs or a process of innovation inspired by nature.
In the worldwide, the United States is a leader in Biomimicry, and the latter is becoming increasingly important with New Research and Projects. Germany is the European leader with more than 80 research groups, the universities of Stuttgart, Freiburg and Tübingen, Germany, have joined forces to create a center of excellence dedicated to the bio-inspired design of building structures (Raskin, 2017).

Biomimicry design is not only adapting the design from the nature but also considering how to use nature's effective functions such as heating and cooling system (Rajshekhar Rao, 2014).

The historical part allowed becoming aware that nature has always been a reference for every population. Here are some historical landmarks (Figure 1) that spotted this evolutionary approach: 


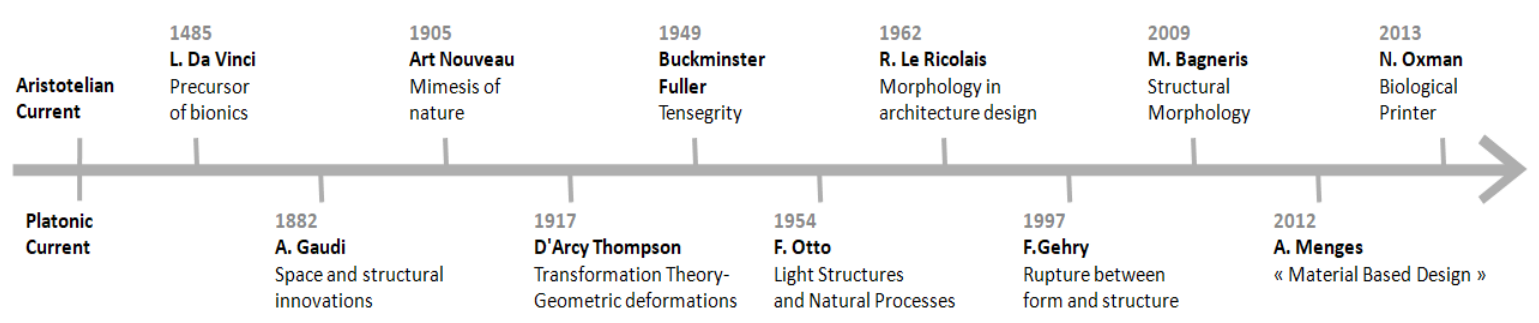

Figure 1. Architecture and the evolution of naturalistic thought. Source: Adeline STALS.

The term Biomimicry appears since 1980 by the biologist and environmentalist Janine Benyus, the author of the book "Biomimicry: Innovation Inspired by Nature" Benyus suggests looking at nature as a Model, Measure, Mentor.

In the scientific conceptualization, J. M. Benyus (1997) proposed as a definition of Biomimicry: "Innovation approach, which involves the transfer and adaptation of the principles and strategies developed by living organisms and ecosystems, to produce goods and services in a sustainable manner, and to make human societies compatible with the biosphere ... "

\section{Architecture follows nature}

Nature always offering immense inspirations and ideas to designers for creating architecture. Nature is demonstrably sustainable, her challenges have been resolved over eons to enduring solutions with maximal performance using minimal resources (Nori Oxman, 2010).
We always need to go back to nature, and architecture considered nature as a source of inspiration. As we have seen, the Biomimicry is that science which makes the intersection between biology and other disciplines, and this approach always asks the following questions:

How does nature help us to innovate? And how we can develop the architecture filed or other science from the concept of the bio-inspiration?

According to Frei Otto, the biology has become indispensable for architecture but architecture has also become indispensable for biology. In architecture, the bioinspiration is perceived as a better method to answer the stakes of the design of forms and efficient structures, of energy efficiency and also at the level on the urban scale (Raskin, 2017), and the materials are also made by nature (Benyus, 2011). The goal of biomimetic architecture is not only to shape and measure space but also to develop synergistic relationships between the building and its environment (Chayaamor-Heil, 2018).
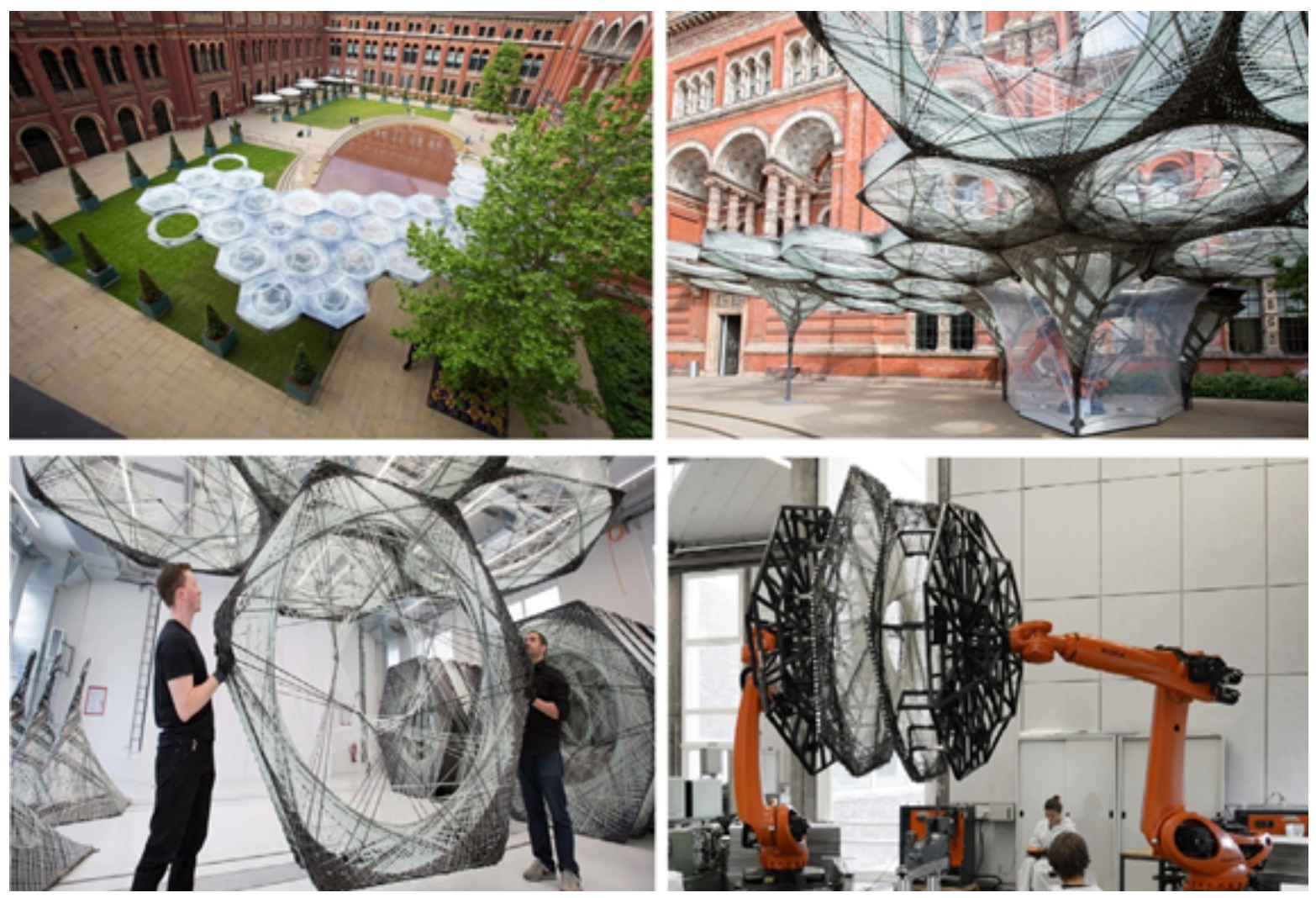

Figure 2. Elytra Filament Pavilion for Victoria \& Albert Museum in London. With the using of robotics technologies (https://www. designboom.com/architecture/elytra-filament-pavilion-robotic-fabrication-victoria-and-albert-museum-london-05-18-2016/). 
The biomimetic approach

The Biomimetic Concept:

Biomimicry $=$ Science $X+$ Biology .

Science $X=$ Engineering, Architecture, Agricultural, Design, Mechanics, Industrial, Robotics, Management etc. Biomimicry or bio-inspiration approaches are very diverse, we consider the biomimetic design process as a whole, from the initial idea to the final product, and two approaches have been identified (Chayaamor-Heil, Guéna, 2018).

The first part concerns the design problem and then examines the ways in which organisms or ecosystems found in nature solve this problem. The second approach is to identify a particular characteristic, behavior, or function in an organism or ecosystem, and then look for the design problem that could be addressed.

We can distinguish in the process three main sections (Chayaamor-Heil, Guéna, 2018):
1- The search for the biological basis.

2- The abstraction of the results.

3- Implementation in design and technology.

Biomimicry, which is one of the most important science, by functionalities and by systems, which we can find and observe in Nature to develop sustainable innovations from an ecological point of view. This concept of innovation has a lot of advantages and a practical point of view.

The three levels of biomimicry in architecture:

Many of the architects developed architectural projects and constructions at the crossroads between biology and computer science and architecture. This development is at two levels the theoretical level and the practical level,

For example, Frank Gerry's works, characterized by wild, rupture entre la form and function, sweeping curves, and other projects which they use the advances

Table 1. Three possible levels of imitation and their description.

\begin{tabular}{|c|c|c|}
\hline The three levels of imitation & The approaches & Description \\
\hline \multirow[t]{3}{*}{ The level of the organism } & \multirow[t]{3}{*}{ Formal } & $\begin{array}{l}\text { At the organism level corresponds to a biomimetic shape or surface. It is a } \\
\text { question of the inspiration from forms found in nature. The organisms in na- } \\
\text { ture and their morphology are perfectly adapted to the environment in which } \\
\text { they live. }\end{array}$ \\
\hline & & The projects \\
\hline & & $\begin{array}{l}\text { Elytra Filament Pavilion (Figure } 2 \text { ) in Victoria \& Albert Museum in London } \\
\text { which is an impressive example which explains the intersection between } \\
\text { architecture and biology and the robotics. Its individual modules were defined } \\
\text { by an algorithm and then produced with the help of an industrial robot, } \\
\text { realized by a team from the University of Stuttgart. The second project is the } \\
\text { design of the Art-Science Museum was inspired by the lotus flower (Figure3). } \\
\text { The particular arrangement of the petals that make up the building allows } \\
\text { rainwater to be collected for recycling and lets in natural light in several } \\
\text { decreasing directions. }\end{array}$ \\
\hline \multirow[t]{3}{*}{ The level of behavior } & \multirow[t]{3}{*}{ Functional } & $\begin{array}{l}\text { At the behavior level corresponds to the function. It's about observing how } \\
\text { nature performs a function. }\end{array}$ \\
\hline & & The projects \\
\hline & & $\begin{array}{l}\text { One of the examples of the biomimetic technical solutions, the work of } \\
\text { architect Mick Pearce illustrates the level of behaviour of Biomimicry in the } \\
\text { Eastgate Building in Harare, Zimbabwe. It is partly based on ventilation and } \\
\text { temperature control techniques observed in termite mounds in order to cre- } \\
\text { ate a stable thermal environment inside the building (Figure 4). This passive } \\
\text { ventilation system considerably reduces energy consumption. }\end{array}$ \\
\hline \multirow[t]{3}{*}{ The Level of ecosystem } & \multirow[t]{3}{*}{ Eco-systemic } & $\begin{array}{l}\text { The ecosystem-level corresponds to imitate ecosystems found in nature } \\
\text { and considered as a means of increasing the sustainability of an architec- } \\
\text { tural project. It is about understanding how relationships between species } \\
\text { and their environment produce an ecosystem and It is characterized by his } \\
\text { organization, hierarchy, interdependence, Dynamic, Adapted. The world's } \\
\text { ecosystems are very complex and those characteristics what keep the planet } \\
\text { as a whole in balance. }\end{array}$ \\
\hline & & The projects \\
\hline & & $\begin{array}{l}\text { Among the examples, the Sahara Forest Project in Tunisia is a new environ- } \\
\text { mental solution designed to utilize what we have enough of to produce what } \\
\text { we need more of using deserts, saltwater, sunlight and } \mathrm{CO}_{2} \text { to produce food, } \\
\text { water and clean energy. }\end{array}$ \\
\hline
\end{tabular}




\section{Architecture and Engineering Volume 3 Issue 4}

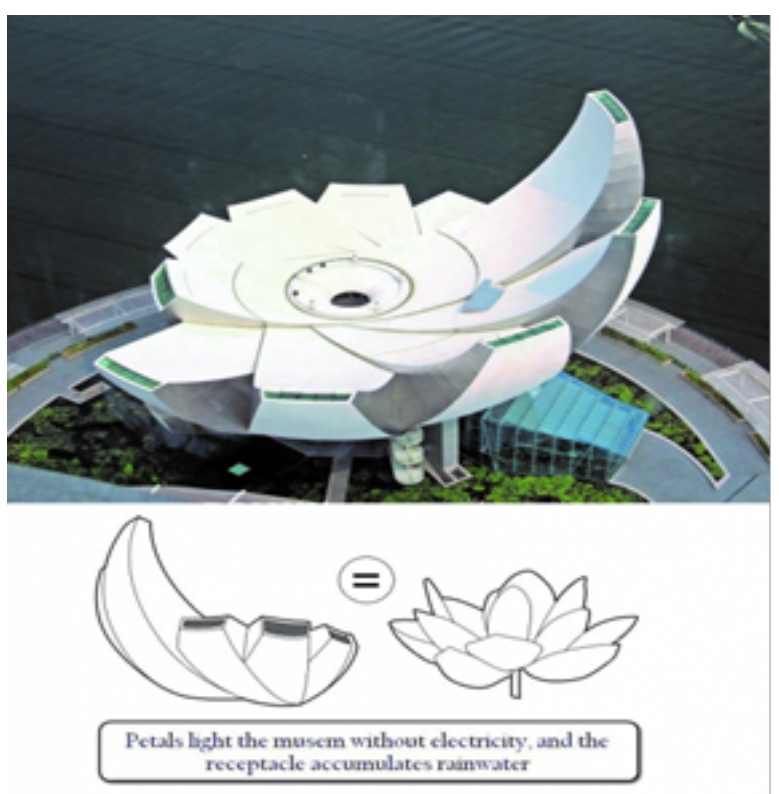

a

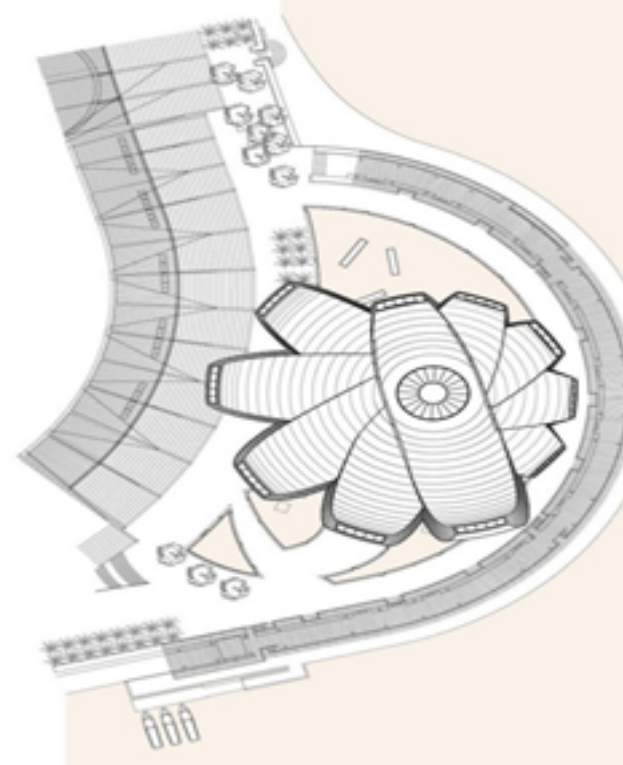

b

Figure 3. $a$ - The Art-Science Museum, designed by architect Moshe Safdie, inspired by the lotus flower. b - Roof plan of the museum. Singapore (https://journals.openedition.org/craup/309, https://www.area-arch.it/en/artscience-museum/).

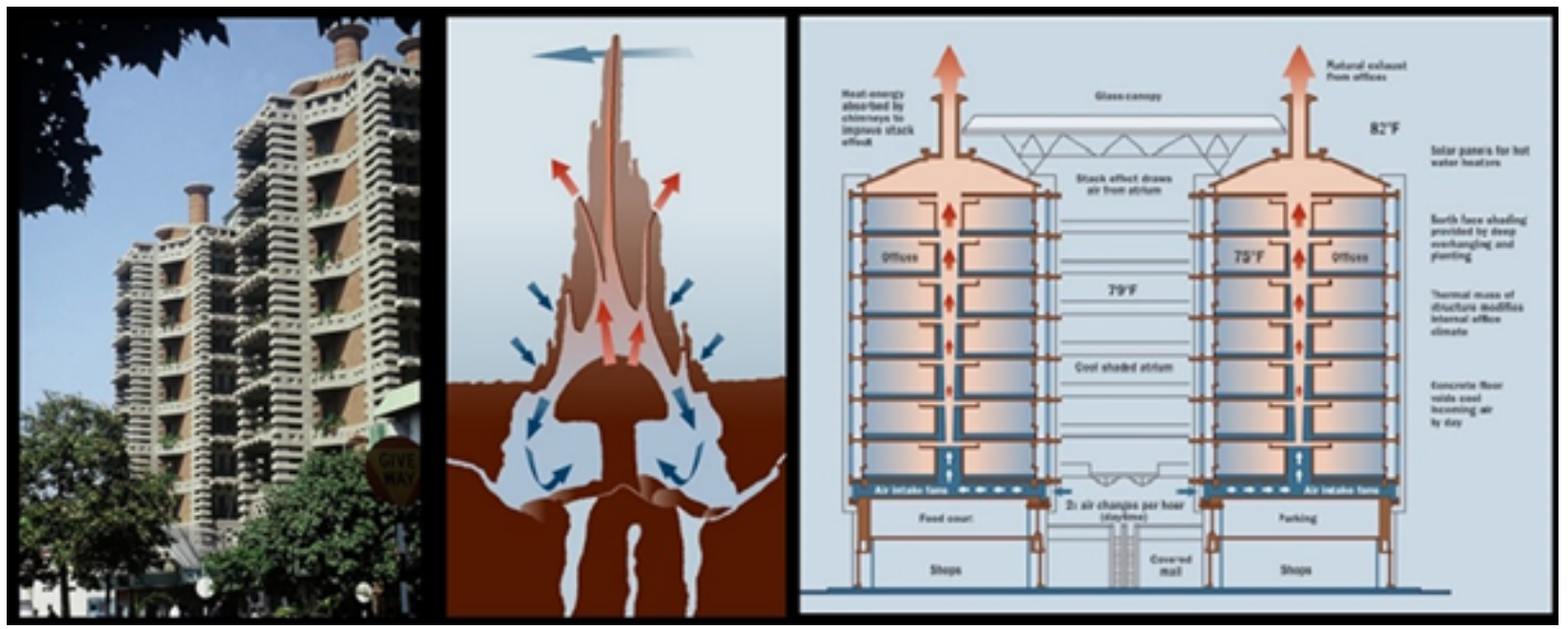

Figure 4. The termite mound ventilation system and the application of the termite mound operation to the natural ventilation of the Eastgate Building (https://journals.openedition.org/craup/309).

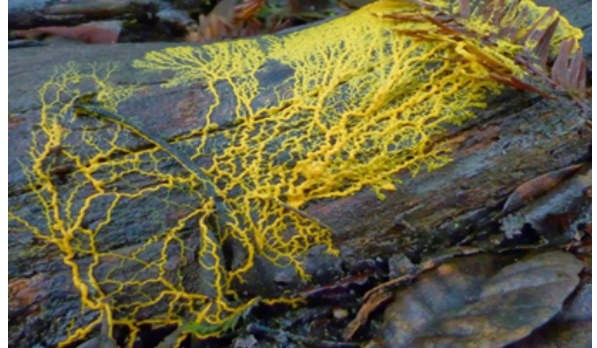

Figure 5. Physarum polycephalum in his Natural habitat (http:// sweetrandomscience.blogspot.ru/2014/01/le-metro-de-tokyo-et-lesroutes-des.html).

in 3D printing technology are often lauded as examples of biomimetic architecture.

The biomimetic design processes in architecture reveal three possible levels of imitation: the level of the organism, the behavior or the ecosystem (URBEO, 2010).
A biomimetic algorithm. A gooey Mold inspires the design of transport networks

When a team of Japanese and Hungarian researchers discovers that a kind of gooey Mold called Physarum Polycephal (Figure 5) is able to find its way in a labyrinth (Madjer, 2014). This Mold seems to be intelligent and able to explore its environment to find the shortest paths to food, and this was the first biological basis which was the base for the project.

Here is how the researchers proceeded to reproduce, at the scale of Physarum, the problematic of the network of Tokyo, which connects the capital to the 36 neighboring cities: they had 37 food points, corresponding to the 36 cities and Tokyo, in a box Petri, trying to respect the geography of the region. Then, they implanted Physarum at the point corresponding to Tokyo (the yellow dot in 

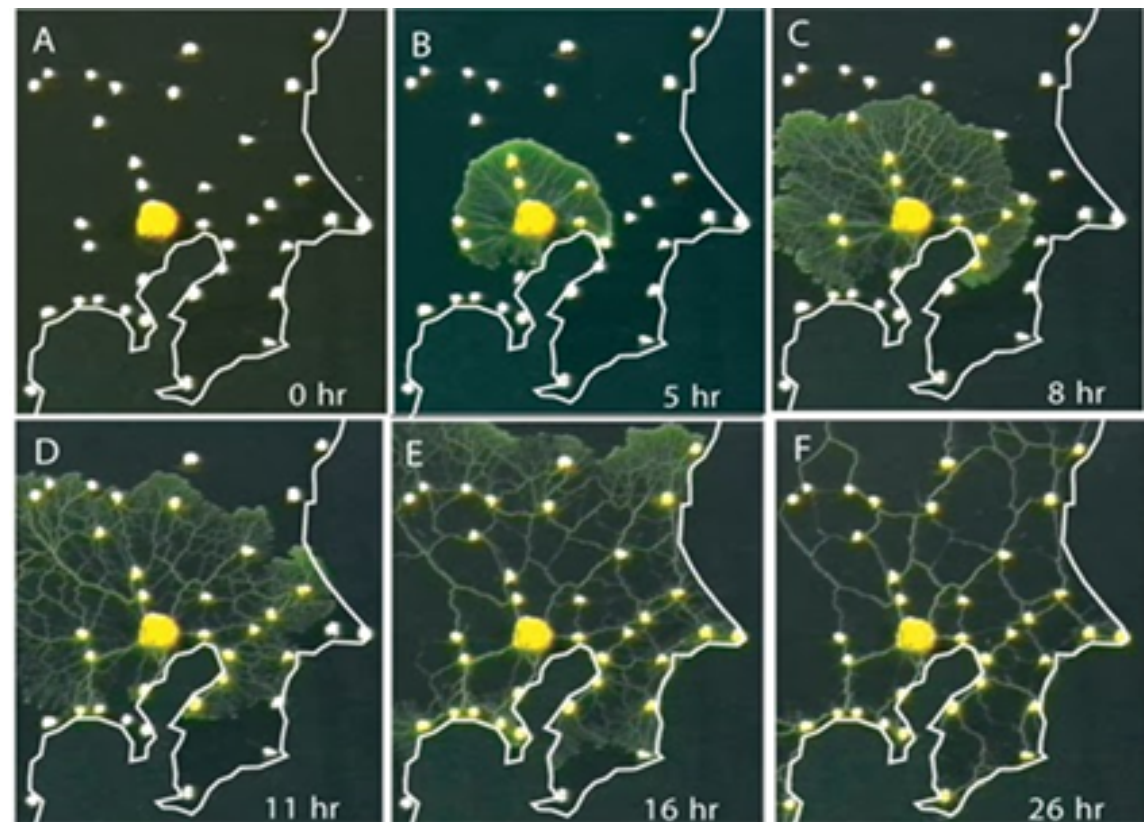

Figure 6. The evolution of the Physarum network in a Petri dish representing the Tokyo region (http:// sweetrandomscience.blogspot.ru/2014/01/le-metro-de-tokyo-et-les-routes-des.html).

Figure 6 below) and observed how the Mold was growing (Chayaamor-Heil, Guéna, 2018).

On the basis of these observations, an algorithm is constructed that mimics the behavior of the Physarum Polycephal: the Physarum Solver. This algorithm is able to find an optimal path in a network and be more efficient. This amazing algorithm can, for example, solve problems of optimization of a transport network. And give us the optimal answer of how we can connect cities in a minimum of lines with maximum efficiency and performance.

The examples of bio-inspiration are numerous, this review proposes to review the project's applications of this approach and identify the characteristics and methods of innovations and her development.

The examples presented show that the architectural biomimetic approach is an interdisciplinary approach combining biology and architecture and can give us the most optimal solutions to any architectural problems or for the new project's designs.

We can also mention the project designed by Achim Menges. This architect reproduces the biological principles of the pine cone (Figure 7). Indeed, it has developed a particular hygroscopic behavior, according to the moisture content of the air, it opens or retracts.
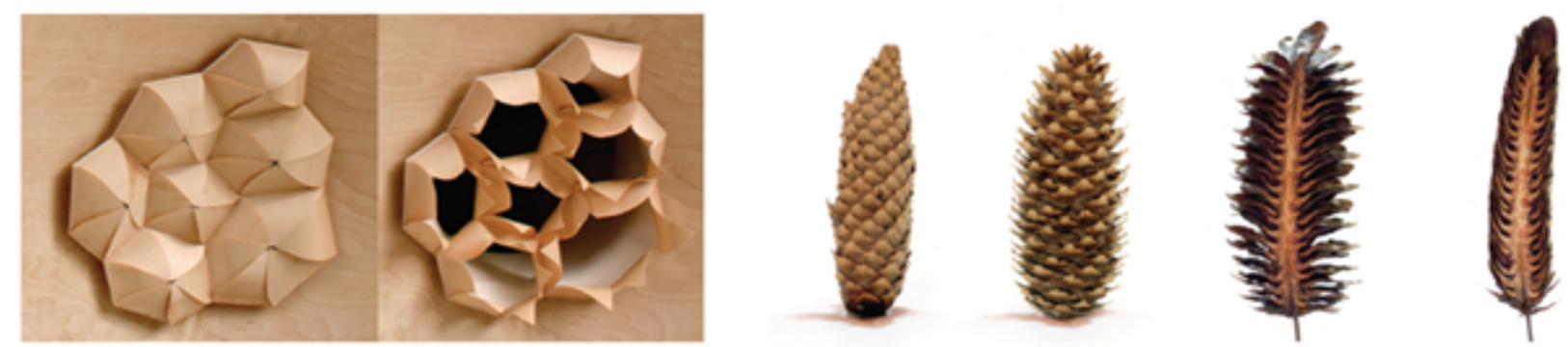

Figure 7. The biological principles of the pine cone, HygroSkin Meteorosensitive Pavilion (http://www.anabf.org/pierredangle/magazine/ europe-et-international/architecture-bio-inspiree-vers-la-conception-dhabitats-r-g-n-ratifs)

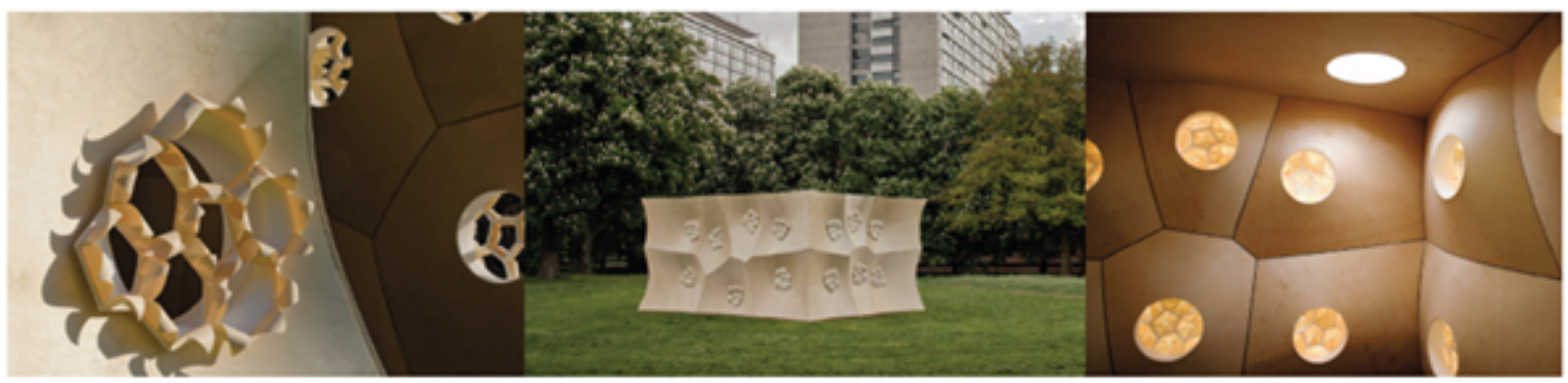

Figure 8. HygroSkin Meteorological Hall, Achim Menges in collaboration with Olivier David Krieg and Steffen Reichert, University of Stuttgart (http://www.anabf.org/pierredangle/magazine/europe-et-international/architecture-bio-inspiree-vers-la-conception-dhabitats-r-g-n-ratifs) 


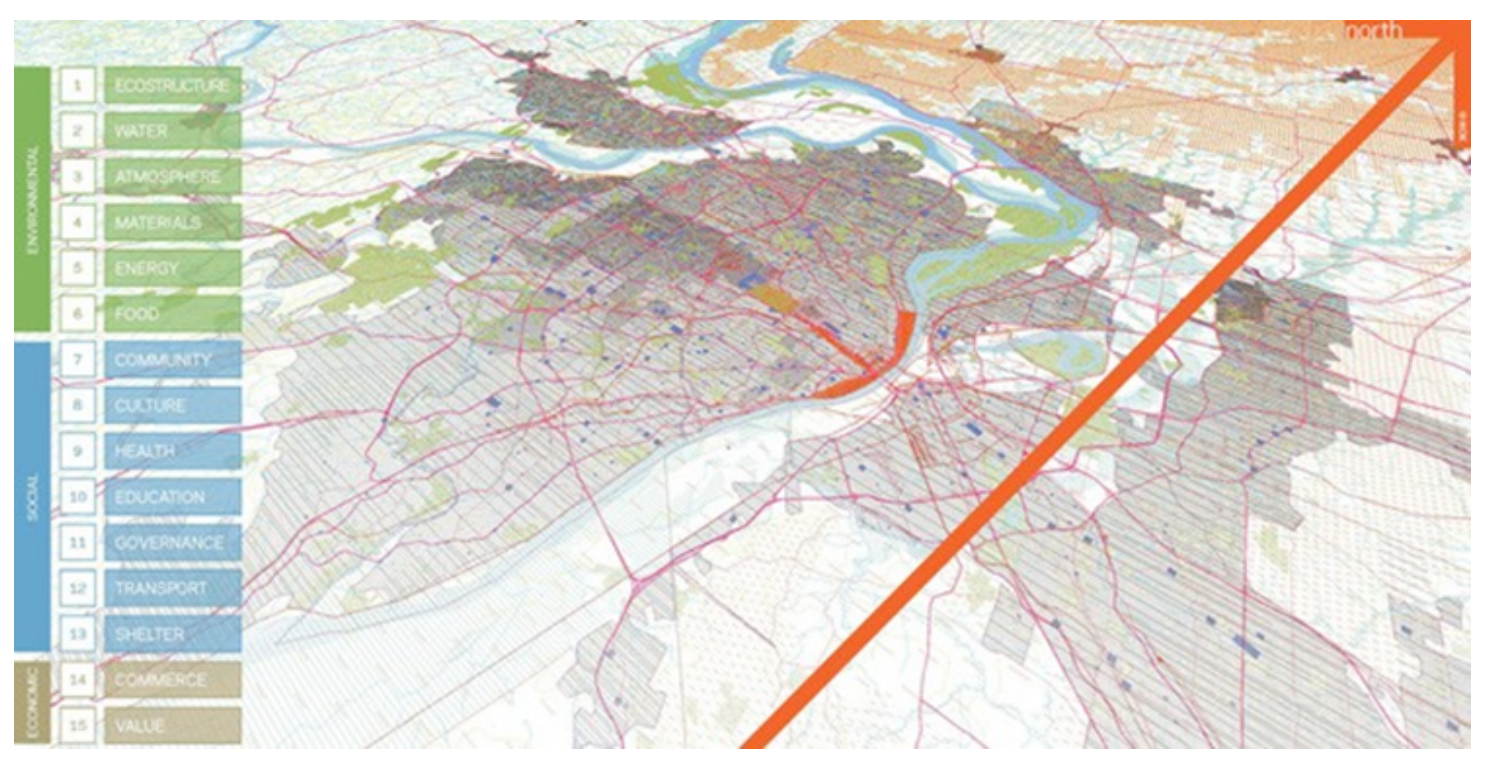

Figure 9. Interface or the framework for FIT approach, Fully Integrated Thinking ${ }^{\mathrm{TM}}$ (http://www.hok.com/thought-leadership/fully-integrated-thinking/).

This phenomenon and the anisotropy of wood, in general, to understand and thus apply to architectural elements and represent the behavior level corresponds to the function.

In 2012, he designed HydroSkin, Meteorosensitive Pavilion (Figure 8), typically conceived as a technical function which reacts to climatic variations. Nature has evolved a variety of dynamic systems interacting with climatic conditions like the pine cone. For Achim Menges he starts from the material to generate the form, it is the characteristic of the trend of the material-based design.

At the intersection between biology and architecture, computer sciences

The world of biology is a great source of inspiration for the work of architects. For example, the architect Frei Otto's interest in biology is explained by his design of Lightweight constructions. While the Japanese Metabolists were interested in the biological processes of growth because they could apply to urban structures, Frei Otto was passionate about the optimization of natural structural forms. Frei Otto's interest in biology is explained by his recognition that the processes of evolution of natural forms are due to the biological laws of selection that generate lightweight constructions (Stals, 2013).

The mathematical, biological, physical developments and also computer advances of recent decades and the appearance of bionics, refocus attention on natural morphologies. Whatever the computer and mathematical methods at the heart of these various software programs, the increasing amount of data to be processed brings the actors of this form of bioinformatics to develop them more and more [Georgia Barlovatz-Meimon, Sylvain Sené, 2018].

Computer science, considered as a science or technology, has a growing role in the development of research in biology (Barlovatz-Meimon, Sené, 2018), and in architecture and other sciences. The advent of computing has facilitated the design and modeling of complex shapes. The 2000 s are marked by the emergence of "genetic algorithms". Genetic algorithms are a type of optimization algorithm, meaning they are used to find the maximum or minimum of a function (Carr, 2014), that is to say, mathematical formulas based on techniques derived from genetics and natural evolution to generate forms and develop new optimization models. In architecture, this means formalizing the design process according to a set of specific procedures and instructions. Algorithms the logical sequence of determined operations that allows a problem to be solved mathematically.

What happens at the intersection of data and design? This question was the inspiration behind a process for innovation called Fully Integrated Thinking ${ }^{\mathrm{TM}}$, or FIT. One of the interesting data-design projects it's The FIT is an approach which is the intersection of data and design. Currently being further developed by a global collaboration of designers, biologists, Architects and other partners, the FIT "Fully Integrated Thinking" process identifies the questions we need to ask of our work to achieve more sustainable outcomes.

The FIT framework enables us to tap into the wisdom behind the natural, social and ecological systems of a place to inform design and decision-making. It allows us to find answers to today's design challenges by emulating 3.8 billion years of nature's genius (http://www.hok.com/ thought-leadership/fully-integrated-thinking/).

\section{Material-Based Design}

One of the new approaches in architecture and design is the Material-based Design Computation is developed and proposed as a set of computational strategies supporting the integration of form, material and structure by incorporating physical form-finding strategies with digital analysis and fabrication. In this approach, material precedes shape, and it is the structuring of material properties as a function of structural and environmental 


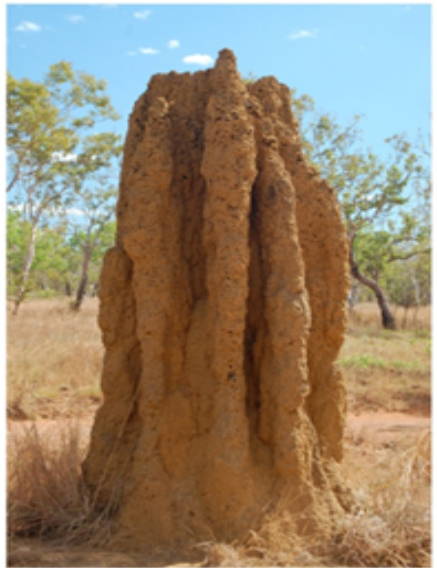

a

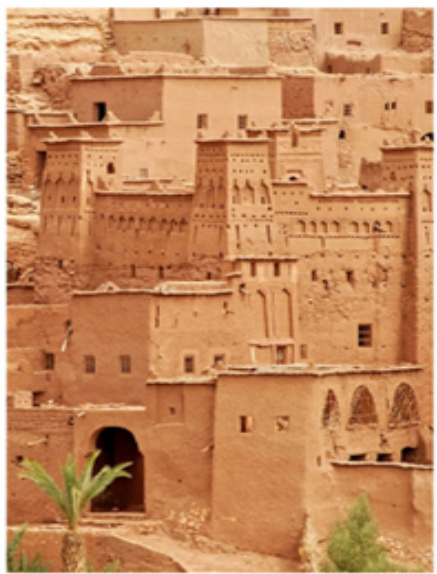

b
Figure 10. a - Termite Hill, Namibia, b-Ksar Ait Benhaddou, built from clay material as the Termite Hill (The formal similarity)

performance that generates design form. Material-based Design is a unique approach to computationally-enabled form-finding procedures, and experimentally investigates how such processes contribute to novel ways of creating, distributing and depositing material forms. The architects or designers are now able to establish parametric relationships between features, methods, and functions in a way that supports design processes of a generative nature (Oxman, 2010).

Material based Design Computation promotes an integrated approach to design, whereby material properties inform the geometric generation of highly complex 3-D surface structures, However, geometrical considerations, mainly, currently drive this liberation, which seems to be manifesting itself across the board throughout the continuous phases of the design process. Generative performative modelling approaches have been introduced that engage principles of engineering with form finding (Nori Oxman, 2009).

For computational design strategies there's too many new developments in digital fabrication, particularly in robotics fields, allow for the implementation of design principles such as heterogeneity, hierarchy, or anisotropy in architecture, which are characteristic principles found in nature. One of the examples, the fabrication of ultralightweight timber shells in architecture. Specifically, a robotic sewing method is developed in conjunction with a computational design method for the development of a new construction system that was evaluated through a large-scale prototype building (Tobias Schwinn, Oliver David Krieg, Achim Menges, 2016).

In recent years there are many sustainable policies with the desire to develop architecture and environmentally friendly designs and the protection of the environment, starting by the sustainable development for several regions of the world, one of them the great Sahara region is one of the most impressive places, by her architectural heritage and her environments, and contains hundreds of old and new cities.

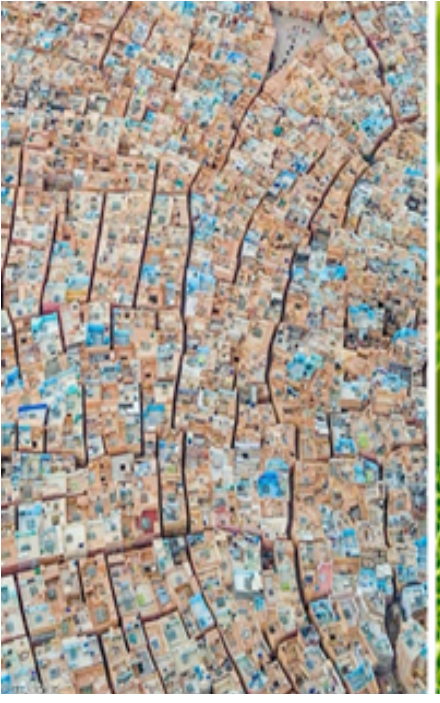

a

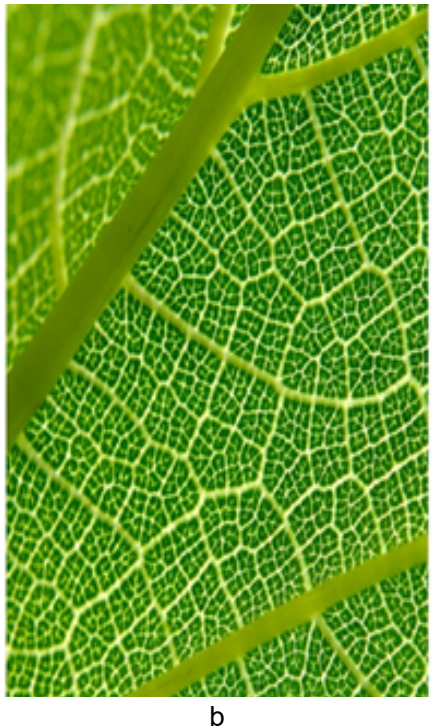

b
Figure 11. $a$ - The road system of Ghardaia city, $b$ - The leaf of tree (The functional similarity).

\section{Ecological Innovation of Saharan architecture by Biomimicry}

With the rapid evolution of the architectural and urban language and the technological acceleration in the field of architecture and facing to the crisis in the new architecture and urbanism, the Saharan cities are recently part of a sustainable policy with the desire to develop the architecture and protect the environment, conserve its biodiversity and encourage sustainable development. The past examples can be a great source of inspiration about the demarche of the processes of conception in the architectural project in the Saharan cities which have a great heritage of architecture, and their cities always represented the concept of ecology and the respect of the environment, more than that, it's can be a soil favourable to great changes.

Traditional architecture in Saharan was based in the design buildings on natural materials and to design passively, the architectural styles and constructions technique are so various as the numerous influences that had inspired them.

The past examples can be a great source for inspiration about the demarche of the processes of conception in the architectural project in the Saharan cities which have a great heritage of architecture, and their cities was always represented the concept of ecology and the respect of the surrounding environment. The architectural styles are so various as the numerous influences that had inspired them.

For all the old population, nature was the first way of inspiration and a great way of understanding how things should be and how things should work, the Vernacular architecture is an example of an architecture which adapts to harsh climatic conditions, and which is born from nature and build by the using of natural material (Figure 10 ) and which represent the basic form of the Biomimicry approach but this architecture didn't develop with time and with the new needs. 


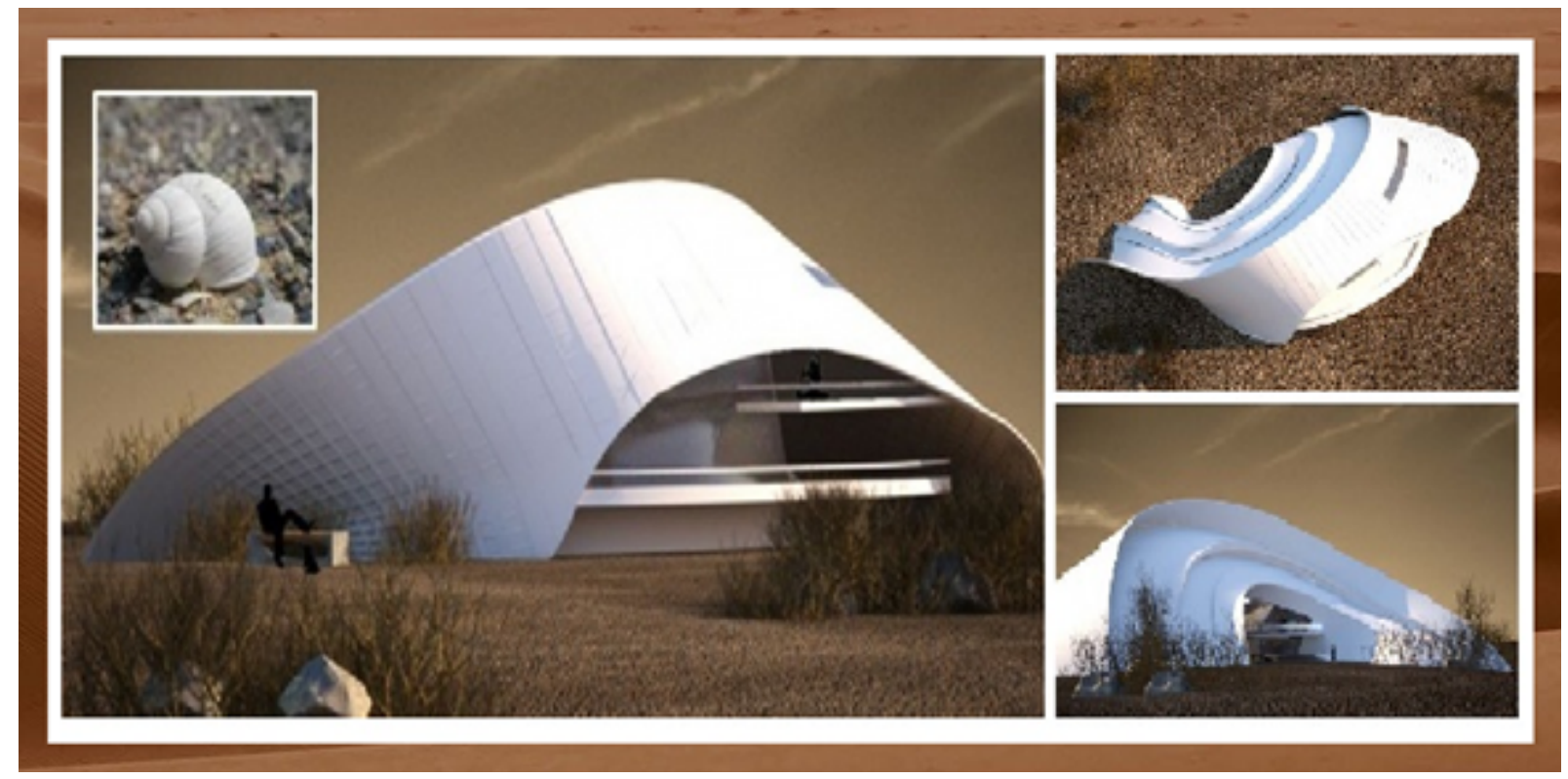

Figure 12. Curvy Desert Home Designed by Iranian Students Mimics the Snail (https://www.greenprophet.com/2012/03/iran-desert-mimics-snail/)

The desert construction has always been effective in terms of adaptation to the harsh conditions of the terrain and climate. The cities are made in the forms of traditional architecture and natural materials largely due to the influence of the surrounding environment. Houses are compact with a closed outer face. The layout is similar in most of the villages (De Filippi, 2006) this layout of roads are based on tree system as shown below (Figure 11).

Under the pressure and the architectural crisis and the accelerated urbanization in the Saharan cities and the imperatives of sustainable development, the problems of the design of the projects and the modes of management and climate adaptation are strongly imposed. The new urban and architectural projects that exist in the Saharan context in the desert cities of North Africa are very reliable in terms of energy efficiency and in terms of the relationship between buildings and nature, According to Christophe Menezo (INSA / EDF), buildings consume $50 \%$ of energy resources. And many architects like Frei Otto consider that it is time to demand lighter architecture, more energy efficient, more mobile and more adaptable buildings, more natural buildings, without neglecting the demand for security. The new technologies, like 3D printers, BIM, the algorithms, open up new possibilities and the best innovation in the field of architecture.

The development of the Biomimicry approach takes us for more understanding of how important and interesting to refer nature to the design of an architectural project in a specific context. As a first departure, the relationship with nature is essential and the morphogenesis of the living allows us to understand what were the first fruits of the contributions of biology to architecture. Also aims to facilitate the transfer of knowledge from biology to other disciplines in order to solve technological or governance challenges (Menga, Monnier, 2014). However, the presumed technological and ecological advances are such that the world of Biomimicry and its international actors are now structured, attributing to this new approach a scale characterized by some of the "third industrial revolution" (Iswann, 2018).

The integration of Biomimicry in the innovation strategies of Saharan architecture and urbanism an urgent need to develop and solve engineering and environmental problems.

The future new Biomimicry project of architects and designers can demonstrate the vast potential of traditional architecture, combined with modern design and technologies, materials and construction techniques. we can mention a project which makes by a team of Iranian students "Art University of Isfahan" won a prestigious design competition with this biomimetic dwelling, this curvy desert dwelling, Like the snail, which retreats far into the depths of its shell when the weather is hot, we can mark here that the snail has remarkable qualities that have allowed it to stay both cool and moist in even the harshest temperatures.

For the design team found its form, the material of its shell, and its coping strategies to be qualities worth emulating in architecture (Laylin, 2012). The imitation of form and function of a snail results in a functional, innovative, and energy-efficient architecture that sustains in the hottest temperature of the desert.

We have described the methods proposed for Biomimicry with projects that enriched and showed that there are several possible attitudes for bio-inspiration in architecture and in biomimetic methods, as a rapid development and an innovate approach in which the architect participates in the biomimetic activity in collaboration with biologists and computer scientists.

The use of the Biomimicry approach can take us for more understanding of how important and interesting to refer nature to the design of an architectural project, the relationship to nature is essential and can start by the transfer of knowledge from biology to other disciplines 
in order to solve technological or governance challenges (David Menga, Bernard Monnier, 2014). The integration of Biomimicry in the innovation strategies of Saharan architecture and urbanism an urgent need to develop and solve engineering and environmental problems, the future new Biomimicry project of architects and designers can demonstrate the vast potential of traditional architecture, combined with modern design and technologies, materials and construction techniques.

The biomimetic design methodology capable of producing innovations for Saharan architecture in order to answer the sustainable development issues. The main objective of this article was to present a synthesis of the approach to design and approaches based on Biomimicry and can be a great option for the optimal sustainable development of the desert cities, there are many tools or methods to operationalize the biomimetic approach. Biomimicry certainly offers methods and approaches based on the world of nature but Also the proposed biomimetic approach of solutions also conform to economic, management, social, technological, and technical expectations.

\section{Conclusion}

The inspiration by Nature's is the most optimal strategies which give us an architecture with maximal performance and in the same time with minimal resources without energy wasting. Today, under the imperatives and the intensive growing of the failures and environmental liabilities of the Biomimetic approach, with high performance and exceedingly effective and efficient structures.

For the using of biomimetic approach and the innovation of traditional architecture, firstly we propose the creation of a digital platform with collaboration between architects, biologists, computer scientists, engineers, this platform it's necessary with providing several assistance tools, based on algorithms as well as tools for decision support as the optimization and modulization, and creations of punctual projects in the cities and develop a strategies of an biomimetic renovation of the traditional cities based on a biomimetic approaches

The biomimetic design process from the natural morphogenesis to project design can be as the following step:

1. Identify problems or needs.

2. Determination of the biological basis based on the result of the project requirement or the problem.

3. The abstraction of the results.

4. The modulization and simulation of the model.

5. The Implementation.

The aim of this theoretical work is to explain biomimicry methods and process that have a positive impact on the environment and architecture development, we can be sure that in the field of architecture, the bio-inspiration has a great of potential point to meet the current challenges of designing efficient for forms or structures, energy efficiency and climate and optimization of flows at the urban conditions and many other parameters. The challenge for the coming years is the development of an intelligent platform which can make all this steps based on the database of the behaviour or the form or ecosystem of all organism in nature and give us the most optimal solutions for many problem and innovation design in Sahara.

We can say that the Biomimicry can be as a Renaissance for the Saharan architecture, and for her sustainable development 


\section{References}

Barlovatz-Meimon, G., Sené, S. (2018). Méthodes informatiques en biologie [Computer Methods in Biology]. Lyon: Institut Rhônealpin des systèmes complexes (IXXI), pp. 1-3.

Benyus, J. (2011). Biomimétisme: Quand la nature inspire des innovations durables [Biomimicry: When nature inspires sustainable innovations]. Paris: Rues de l'échiquier. (in French)

Carr, J. (2014). An Introduction to Genetic Algorithms. Available at: https://www.whitman.edu/Documents/Academics/Mathematics/2014/carrjk.pdf. (accessed on 12.09.2018)

Chayaamor-Heil, N., Guéna et Nazila Hannachi-Belkadi, F. (2018). Biomimicry in Architecture: State, methods and tools. Available at: https://journals.openedition.org/craup/309. (accessed on 12.09.2018) (in French)

De Filippi, F. (2006). Traditional architecture in the Dakhleh Oasis, Egypt: space, form and building systems. In: Proceedings of The 23rd Conference on Passive and Low Energy Architecture. Geneva: PLEA2006, pp. 1-6.

Iswann, A. B. (2018). Vers la ville biomimétique, Quand la nature inspire le développement urbain durable [Towards the Biomimetic City, When Nature Inspires Sustainable Urban Development]. Available at: http://www.masterbioterre.com/sites/default/ files/Vers\%20la\%20ville\%20biomim\%C3\%A9tique\%20Ali\%20Benali.pdf. (accessed on 12.09.2018) (in French)

Laylin, T. (2012). Curvy Desert Home Designed by Iranian Students Mimics the Snail. Available at: https://www.greenprophet. com/2012/03/iran-desert-mimics-snail/. (accessed on 12.09.2018)

Madjer, K. (2014). Le métro de Tokyo et les routes des États-Unis modélisés par un micro-organisme [Tokyo subway and US roads modeled by a microorganism]. Available at: http://sweetrandomscience.blogspot.ru/2014/01/le-metro-de-tokyo-et-lesroutes-des.html. (accessed on 12.09.2018) (in French)

Menga, D., Monnier, B. (2014). Le biomimétisme, Comment la nature nous aide à innover [Biomimicry, How nature helps us to innovate]. Palaiseau: École Polytechnique. (in French)

Oxman, N. (2009). Material-Based Design Computation: Tiling Behavior, Computation Group, Department of Architecture, Massachusetts Institute of Technology. Available at: http://papers.cumincad.org/data/works/att/acadia09_122.content.pdf. (accessed on 07.10.2018)

Oxman, N. (2010). Material-based Design Computation. Massachusetts: Massachusetts Institute of Technology.

Rao, R. (2014). Biomimicry in Architecture. International Journal of Advanced Research in Civil, Structural, Environmental and Infrastructure Engineering and Developing, 1 (3), pp. 101-107.

Raskin, K., Cruz, E. (2017). Architecture bio-inspirée : vers la conception d'habitats régénératifs [Bio-inspired Architecture: Towards Regenerative Habitat Design]. Available at: http://anabf.org/pierredangle/magazine/europe-et-international/architecture-bio-inspiree-vers-la-conception-dhabitats-r-g-n-ratifs. (accessed on 12.09.2018) (in French)

Schwinn, T., Krieg, O.D., Menges, A. (2016). Robotic Sewing "A Textile Approach Towards the Computational Design and Fabrication of Lightweight Timber Shells". Available at: http://papers.cumincad.org/data/works/att/acadia16_224.pdf. (accessed on 07.10.2018)

Stals, A. (2013). Nature et architecture, De la morphogenèse du vivant à la création numérique [Nature and architecture, From the morphogenesis of the living to the digital creation]. Liège: University of Liège. (in French)

URBEO (2010). Eco-urbanisme, le Biomimétisme une source pour l'architecture durable, recherche et perspective [Eco-urbanism, Biomimicry a source for sustainable architecture, research and perspective]. Available at: https://ru.calameo.com/ $\mathrm{read} / 002595223 \mathrm{~b} 76153823070$ (accessed on 12.09.2018) (in French) 